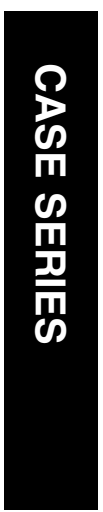

${ }^{1}$ Gloucestershire Eye Department

Cheltenham General Hospital Sandford Road

Cheltenham, UK

${ }^{2}$ Bristol Eye Hospital Lower Maudlin Street Bristol, UK

${ }^{3}$ Southampton Eye Unit

Tremona Road

Southampton, UK

Correspondence:

RL Johnston

Gloucestershire Eye

Department

Cheltenham General Hospital

Sandford Road

Cheltenham GL53 7AN, UK

Tel: + 441242272529

Fax: + 441242272585

E-mail: rob.johnston@

egnhst.org.uk

Received: 18 November 2003

Accepted: 10 March 2004

Published online:

17 September 2004

See acknowledgements for other sites and individuals that contributed data.

Financial interest declaration: Robert L Johnston is a Director of Medisoft Limited. John M Sparrow, Chris R Canning, Derek Tole and Nick C Price have no financial interests.

This work was presented at the South West

Ophthalmological Society meeting in October 2003

\title{
Pilot National Electronic Cataract Surgery Survey: I. Method, descriptive, and process features
}

\begin{abstract}
Aim The primary aim of this large pilot survey was to demonstrate the use and benefits of electronic data collection with respect to rapidly monitoring the access, delivery, and outcome of cataract surgery in the NHS and to update benchmark standards for these parameters of care.
\end{abstract}

Method Eight NHS departments that currently use specialty-specific electronic clinical systems or Electronic Patient Records (EPR) to collect a minimum preoperative, operative, and anaesthetic data set for cataract surgery agreed to pool their data.

Results A total of 162 surgeons from 50 consultant teams and eight NHS Trusts agreed to submit their data on a total of 16541 operations for age-related cataract. This report describes the age, sex, and ethnic profiles of the patients, waiting time for surgery, ocular copathology causing a reason for a guarded visual prognosis, visual impairment on admission, visual acuity in the operated eye, and the characteristics of the anaesthetic and surgical procedures.

Conclusions This survey has raised the benchmark standards established by the last National Survey in 1997. There has been a near universal switch to day case, phacosurgery under local anaesthesia (all used in $\geq 99.1 \%$ of cases compared with 70,77 , and $86 \%$, respectively in 1997). The visual impairment in the operated eye is lower with $45 \%$ having $6 / 12$ or better compared with $27 \%$ in 1997 . Waiting times and visual impairment in the fellow eye have probably improved although data collection for these variables was incomplete. All departments require specialty-specific clinical systems to efficiently collect and analyse these data and this survey proves their potential to form the
RL Johnston', JM Sparrow², CR Canning ${ }^{3}$, D Tole ${ }^{2}$ and NC Price', UK Cataract EPR users group

basis for national electronic surveys in the future.

Eye (2005) 19, 788-794. doi:10.1038/sj.eye.6701644; published online 17 September 2004

Keywords: cataract; audit; process; visual impairment; surgery; electronic

Introduction

Cataract surgery is the most commonly performed operation in the NHS with more than 270000 performed in England in 20022003. ${ }^{1}$ The Royal College of Ophthalmologists (RCOphth) has previously hosted and run two National Cataract Audits in $1990^{2-4}$ and 1997. ${ }^{5,6}$ Both National Surveys were, in part, designed to encourage all UK consultants to perform regular audit of their cataract surgery results and to provide benchmark standards by which surgeons and departments could judge their performance. They also provided a detailed description of the organisation of services and regional variations in access.

The organisation of cataract services has changed profoundly over recent years, especially following the 'Action on Cataracts' programme. There is no up-to-date description of the variation in the organisation of services and clinical outcomes throughout the UK. Few hospital eye departments have invested in the necessary IT infrastructure to prospectively collect clinical data and audit their results. As a consequence few surgeons, managers, purchasers of healthcare, or patients have a detailed knowledge of the results they can expect. This situation falls short of expected professional standards and fails to meet the demands of clinical governance outlined in the NHS Plan. ${ }^{7}$ 
Several units in the UK have recognised this failing and have purchased specialty-specific clinical systems or Electronic Patient Record (EPR) systems that facilitate detailed prospective data collection. This report is the first of a series of studies where clinicians from several of these units have pooled their data to update benchmark standards and to highlight changes in clinical practice and outcome since the last National Cataract Surgery Survey. It is expected that more Eye Units will contribute their data in the future and that subsequent reports will increasingly reflect National trends.

\section{Aim}

The primary aim of this large pilot survey was to demonstrate the benefits of electronic data collection with respect to rapidly monitoring the access, delivery, and outcome of cataract surgery in the NHS and to update benchmark standards for these parameters of care.

\section{Method}

The study design was a prospective cross-sectional survey of NHS eye departments that have used one of two EPR systems for collection of a minimum cataract data set throughout patients' cataract care pathway for at least 12 months. The EPR systems from which data were extracted were 'Medisoft Ophthalmology' by Medisoft Limited (www.medisoft.co.uk) and 'Hospital Integrated Clinical Support System' (HICSS) by Scorpio Information Systems Limited (www.scorpio-is.co.uk). The content of the Medisoft data set and its functionality were initially designed by one of the authors (RLJ) to deliver detailed audit of cataract surgery, but have been refined over the last 7 years in light of customers' comments. The HICSS ophthalmology system is in use in one of the contributing departments and was designed in conjunction with one of the authors (CRC) for similar reasons. Both systems have been used to inform the development of the Cataract National Dataset. All consultants in departments that have used such systems for at least 12 months were invited to submit their team's data. The exact study period for each site varied depending on the date the system was implemented, but ran from the date of implementation (1998-2002) until the day the data were submitted in 2003 and always recorded consecutive cases. At one site, data entry for several of the consultants was initially retrospective but also recorded consecutive cases. All data were e-mailed to, or remotely extracted by, a central source and immediately anonymised to prevent identification of individual patients, healthcare professionals or hospital locations associated with each clinical episode.
To allow direct comparison with the previous National Cataract Surgery Surveys analysis was restricted to patients undergoing surgery for age-related cataract either alone or combined with surgery to reduce astigmatism. Those patients undergoing other combined procedures or surgery for other causes of cataract were excluded.

Mode of data entry into the EPR varied at each site. When used as a networked solution throughout the hospital, the EPR was always linked to the hospital patient administration system for downloading patient demographic data. When used optimally, data were entered directly into the EPR at every step of the patient care pathway (initial clinic visit, biometry, nurses' assessment, in the operating theatre, at the postoperative clinic visit, and entry of data returned from community optometrists). Duplication of data entry was always avoided. At every stage of the care pathway, a paper copy could be printed off for the hospital notes if required. At two sites, individual consultant teams used the EPR on 'laptop' computers that were not linked to the hospital patient administration system.

The minimum preoperative data set included; patient age and sex, preoperative visual acuity with the patient's habitual correction in the operated eye, cataract morphology, reasons for a guarded visual prognosis, axial length, keratometry, and predicted postoperative refraction. The minimum operative and anaesthetic data sets included details of the technique used, complications and grade of surgeon, and the anaesthetist. A wide variety of additional data collection was possible at each stage of the care pathway but was not mandatory. The results of some of these incomplete data sets are also presented.

At seven of the eight sites, data entry in the operating theatre was directly into the EPR by the operating surgeon, which ensured a complete and detailed data set of anaesthetic and surgical details and complications. Entry of postoperative data varied at different sites, either being directly into the system 'live' in clinic, later from paper proformas, from returns from community optometrists, or a combination of these methods.

\section{Results}

Eight NHS Trust sites with 50 consultant teams (162 surgeons) agreed to submit their data. One site declined the invitation to submit data. The sites and surgeons that contributed data were widely distributed throughout the UK and are all listed in the acknowledgements at the end of this paper. The number and percentage of operations contributed by each site are listed in Table 1 along with the time period over which data were collected. 
Table 1 Contribution by each site

\begin{tabular}{lccc}
\hline Site & Time period & Number of cases & Percentage of total cases \\
\hline 1 & $2001-2003$ & 1203 & 7.27 \\
2 & $2000-2003$ & 1572 & 9.50 \\
3 & $2000-2003$ & 575 & 3.48 \\
4 & $2000-2003$ & 3806 & 23.01 \\
5 & $2001-2003$ & 2687 & 16.24 \\
6 & $1998-2003$ & 521 & 3.15 \\
7 & $2002-2003$ & 1024 & 6.19 \\
8 & $2000-2003$ & 5153 & 31.15 \\
\hline
\end{tabular}

The total number of cataract operations examined in this study was 16541 with $63 \%$ of operations on women and $37 \%$ on men and $95.7 \%$ performed between January 2001 and the date of submission of data in April 2003 (seven sites) or September 2003 (one site).

\section{Demographic data, waiting times, and preoperative reasons for a guarded visual prognosis}

\section{Age}

Data on the patient's age at the time of surgery was collected for 16510 operations (99. 8\%). Where patients underwent surgery in both eyes, the age at the time of surgery for each eye was entered as appropriate. The mean age (SD) of all patients was 76.1 (10.2SD) years with the mean age of women being 77.2 (9.7SD) years compared with 74.6 (10.9SD) years for men. No reliable data were available for how many operations were performed on first compared with second eyes.

\section{Ethnic origin}

Data on ethnic origin were collected on 8706 operations (52.6\%). and are shown in Table 2. At all sites the vast majority of patients were Caucasian.

\section{Waiting time - from clinic visit until surgery}

In total 8885 operations $(53.7 \%)$ had data regarding their time on the waiting list entered onto the EPR. Grouping all data from the eight sites, the average wait was 176

Table 2 Ethnic origin ( $n=8706,52.6 \%$ of all operations)

\begin{tabular}{lrcc}
\hline Ethnic origin & $n$ & Percentage & Range by site \% \\
\hline White & 8496 & 97.66 & $89.57-99.17$ \\
Indian subcontinent & 137 & 1.57 & $0-9.98$ \\
Black-African/Caribbean & 22 & 0.25 & $0-1.29$ \\
Chinese & 6 & 0.07 & $0-0.14$ \\
Mixed/other & 45 & 0.52 & $0-0.97$ \\
\hline
\end{tabular}

days (approximately 5.9 months). Overall, $27.3 \%$ of patients were operated on within 3 months of their clinic visit, $52.6 \%$ within 6 months, $84.1 \%$ within 9 months, $95.1 \%$ within 12 months and $99.5 \%$ within 18 months. There was, however, a three-fold difference in the mean wait between sites, varying from 3.1 months at the quickest site to 9.5 months at the slowest.

\section{Reasons for a guarded visual prognosis on admission (ocular copathology)}

Recording the presence or absence of ocular copathology that was considered to be a reason for a guarded visual prognosis was mandatory on Medisoft's system and optional on the HICSS system. Only data from Medisoft sites is therefore included in this analysis. Data were recorded preoperatively for 11357 of the 11388 operations on Medisoft's system (99.73\%). No reason for a guarded visual prognosis was identified preoperatively in $84.87 \%$ of cases. The spectrum and percentage of eyes with each type of ocular copathology thought likely to be a reason for a guarded visual prognosis is shown in Figure 1.

\section{Visual impairment on admission}

Visual acuity data were recorded for both eyes on admission with the patient's habitual correction for 10586 of the 16541 operations (64.0\%). The visual impairment (visual acuity in the better eye) prior to surgery is shown in Table 3 along with the range in visual impairment at different sites. Immediately prior to surgery, $79.0 \%$ had a visual acuity of $6 / 12$ or better in their better eye. Using World Health Organisation criteria $1.2 \%$ of patients were blind prior to cataract surgery having a visual acuity of less than 3/60 and 8.7\% were classified as having low vision (visual acuity less than $6 / 18$ but better than and including $3 / 60$ ).

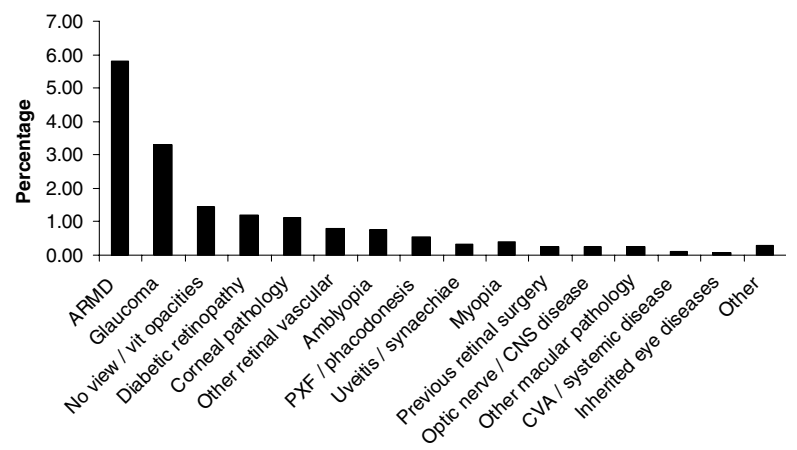

Figure 1 Preoperatively recorded 'Reasons for a guarded visual prognosis' ( $n=1135799.73 \%$ of operations recorded on Medisoft's system). 
Table 3 Visual impairment (visual acuity in the better eye) on admission with habitual correction $(n=10586$ or $64.0 \%$ of the total number of operations)

\begin{tabular}{lrrc}
\hline Visual acuity in the better eye & No. & $\%$ & Range by site\% \\
\hline $6 / 12$ or better & 8358 & 79.0 & $62.9-82.7$ \\
$<6 / 12-6 / 18$ & 1309 & 12.4 & $10.4-25.1$ \\
$<6 / 18-6 / 36$ & 663 & 6.3 & $4.6-12.3$ \\
$<6 / 36-3 / 60$ & 127 & 1.2 & $0.0-3.2$ \\
$<3 / 60$ & 129 & 1.2 & $0.6-2.9$ \\
\hline
\end{tabular}

Table 4 Visual acuity in the operated eye on admission with habitual correction ( $n=16366$ or $98.9 \%$ of all the operations)

\begin{tabular}{lrrc}
\hline $\begin{array}{l}\text { Visual acuity in the } \\
\text { operated eye on admission }\end{array}$ & No. & $\%$ & Range by site\% \\
\hline $6 / 12$ or better & 7385 & 45.1 & $27.3-60.7$ \\
$<6 / 12-6 / 18$ & 3715 & 22.7 & $16.9-28.4$ \\
$<6 / 18-6 / 36$ & 3154 & 19.3 & $13.0-30.9$ \\
$<6 / 36-3 / 60$ & 845 & 5.2 & $2.5-8.8$ \\
$<3 / 60$ & 1267 & 7.7 & $2.8-13.3$ \\
\hline
\end{tabular}

\section{Visual acuity in the operated eye on admission with} habitual correction

Visual acuity with the patient's habitual refractive correction was recorded preoperatively on admission for the operated eye in 16366 cases (98.9\%), shown in Table 4. Overall, $45.1 \%$ of eyes undergoing cataract surgery in this survey had a visual acuity of $6 / 12$ or better.

\section{Characteristics of the surgical procedure}

\section{Day case/inpatient}

Data regarding day case $v s$ inpatient care was available for $100 \%$ of the operations in the data set (16541). Overall, $99.88 \%$ of operations were performed as a day-case procedure. The range of inpatient admission rates between sites ranged from 0 to $0.8 \%$.
Table 5 Anaesthetic technique ( $n=16527$ or $99.92 \%$ of operations)

\begin{tabular}{lrrc}
\hline Anaesthetic technique & $n$ & $\%$ & \% Range by site \\
\hline Peribulbar & 7889 & 47.7 & $0.0-94.1$ \\
Topical alone & 5510 & 33.3 & $0.0-99.4$ \\
Sub-Tenon's & 2771 & 16.8 & $0.4-99.3$ \\
Retrobulbar & 133 & 0.8 & $0.0-2.0$ \\
Combination & 81 & 0.5 & \\
General anaesthetic & 147 & 0.9 & $0.0-5.0$ \\
\hline
\end{tabular}

\section{Anaesthetic}

Details of the anaesthetic technique were recorded for 16527 operations $(99.92 \%)$. The techniques used and the variations by site are shown in Table 5 . Overall, $99.1 \%$ of operations were performed using local anaesthetic techniques.

\section{Operation technique}

The operative technique was recorded for 16538 operations $(99.98 \%)$. Phacoemulsification was used in 16428 (99.3\% range by site $99.2-100 \%)$, phacoemulsification was converted to extracapsular surgery in 24 cases $(0.15 \%)$ and a planned extracapsular technique was used in 86 cases $(0.52 \%)$.

\section{Grade of surgeon}

Data on the grade of the 162 surgeons that contributed to this study was available for 16283 cases $(98.4 \%)$. Consultants performed $55.8 \%$, specialist registrars $25.5 \%$, associate specialists $7.1 \%$, staff grades $7.0 \%$, and senior house officers $3.7 \%$ of all operations. Other grades, such as fellows, performed $1.1 \%$. Details of the number of surgeons and the mean, maximum, and minimum number of operations performed by surgeons of each grade are shown in Table 6.

Table 6 Grade of surgeon (total number of surgeons 162, grade known for 16283 operations, 98.4\%)

\begin{tabular}{lcccccc}
\hline Grade & No. of surgeons & No. of operations & \% of total operations & \multicolumn{2}{c}{ Numbers of operations by individuals of each grade } \\
\cline { 4 - 6 } & & & & Mean & Max & Min \\
\hline Consultant & 50 & 9090 & 55.8 & 182 & 807 & 1 \\
Specialist registrar & 57 & 4157 & 25.5 & 73 & 322 & 1 \\
Associate specialist & 4 & 1156 & 7.1 & 879 & 468 & 1 \\
Staff grade & 13 & 1135 & 3.7 & 19 & 117 & 1 \\
Senior house officer & 32 & 608 & 0.8 & 23 & 84 & 5 \\
Other & 6 & 137 & &
\end{tabular}




\section{Discussion}

This large pilot study demonstrates the potential of specialty-specific electronic patient records to rapidly audit the access, organization, and quality of cataract services throughout the NHS. This is the first large-scale multicentre survey of cataract services since the Action on Cataracts programme and it suggests huge structural changes in the organisation of services have occurred since the last National Cataract Surgery Survey performed in 1997. In all, 50 consultants and their teams working at eight NHS Trusts widely distributed throughout the UK contributed data to this study, but it is not known how representative these units are of activity elsewhere in the UK. The Department of Health hospital episode statistics for England ${ }^{1}$ between 2000 and 2003 allow a crude comparison and show a similar mean age (75 years) and mean waiting time profile (192-175 days) to this data set but a significantly lower use of day-case surgery (85-91\% compared with $99.88 \%$ ).

The age profile of patients with age-related cataract, who have been identified as having a visual problem at the primary care level and have been referred, assessed, and operated on in this survey is almost identical to that in the last National Cataract Surgery Survey. The mean age for all patients in this survey was 76.1 years (74.6 in men and 77.2 in women), compared with 76.3 years (74.3 in men and 77.3 in women) at the time of the last survey in 1997.

Despite the similar age-profile of the patients, the degree of visual impairment prior to cataract surgery (vision in the better eye) was much less severe than in the previous National Cataract Surveys in 1990 and 1997. Using WHO criteria, $1.2 \%$ of patients were blind (visual acuity of less than $3 / 60$ ) and $8.7 \%$ were classified as having low vision (visual acuity less than $6 / 18$ but better than and including 3/60) on admission in this survey compared with 9.1 and $24.6 \% 1990 .^{2}$ The nearest available published comparison from the 1997 survey is $4.0 \%$ worse than $6 / 60$ and $32 \%$ worse than $6 / 12$ in both eyes on admission. The change in access to surgery for patients with mild-to-moderate visual impairment is equally dramatic, with $79.0 \%$ of patients in this study approximately meeting the legal requirement for driving (best-corrected visual acuity in the better eye of $6 / 12$ or better) prior to cataract surgery compared with $49 \%$ in $1990^{4}$ and $68 \%$ in 1997.5

This survey also reveals that patients are now having cataract surgery at milder levels of visual impairment in the operated eye, with $45.1 \%$ of eyes having a visual acuity with habitual correction of better than or equal to $6 / 12$ compared with only $27 \%$ in $1997^{5}$ and $7 \%$ in $1990 .{ }^{4}$ It is less satisfactory to note that there is a three-fold variation in this measure between centres (20.0-60.7\%) which may reflect local underprovision or organisational inefficiencies.

This study differs methodologically from the previous National Cataract Surgery Surveys with respect to recording ocular copathology. Medisoft's system forced preoperative data collection of ocular copathology that was considered to be a 'reason for a guarded visual prognosis' after surgery rather than simply documenting the presence of copathology as occurred in the previous surveys. The copathology had to be identified prior to surgery to avoid bias from clinicians retrospectively identifying copathology in cases that had a poor visual outcome. This probably explains why the percentage of eyes with age-related macular degeneration (5.79\%), glaucoma $(3.29 \%)$, diabetic retinopathy $(1.21 \%)$, and amblyopia $(0.76 \%)$ in this study were much lower than in the last National Cataract Surgery Survey ${ }^{5}$ when they were $16.9,11.2,3.4$, and $1.4 \%$, respectively. The relative merits of these two measures of copathology will be discussed in the paper on clinical outcomes of cataract surgery, and will be helpful in informing the development of the Cataract National Dataset. Scorpio's system did not force data collection on copathology and therefore its data was not included in this analysis.

There has been a substantial improvement in productivity by UK ophthalmologists over the last 13 years with the number of cataract operations in England and Wales increasing from 105000 in $1990^{2}$ to 190000 in 1998-1999 ${ }^{1}$ and 270000 in 2002-2003. ${ }^{1}$ This improvement in the NHS overall has been contributed to by the almost universal switch to day case $(99.88 \%$ in this survey compared to only 8\% in 1990 and 70\% in 1997/1998), local anaesthetic (99.1\% now compared with $46 \%$ in 1990 and $86 \%$ in 1997) phacoemulsification surgery $(99.3 \%$ now compared with $<4 \%$ in 1990 and $77 \%$ in 1997) described by the eight units in this survey. The variation in practice between participating centres of these three important factors that was noted in 1997 has been all but eliminated. Reforms of the care pathway such as those promoted by the Action on Cataracts policy are, however, probably equally important in improving NHS productivity.

Despite a major increase in demand for cataract operations, the average waiting time for surgery in the NHS has declined. ${ }^{1}$ The experience of the eight units in this study reflects the improved national picture with the average wait being 5.9 months compared with 7.4 months in 1997 and only 5\% waited more than 12 months compared with $17 \%$ in 1997 . It is less satisfactory to note that there was still a three-fold variation in average waiting times between sites from 3.1 to 9.5 months.

This study clearly supports the proposition that improved organisation of cataract services allied with a 
modest expansion in the consultant workforce has significantly improved access to cataract surgery in the NHS. The number of operations performed has substantially increased at the same time as surgery is being offered earlier and the waiting times have decreased. Cataract surgery is unique among the commonly performed operations in the NHS in having improved productivity at a time when junior doctors' hours have been reduced and their requirement for supervision increased. ${ }^{1}$

A number of weaknesses of this pilot study should be acknowledged. It is not established whether this study is representative of practice throughout the NHS. The sample is derived from a group of consultants and other grades of surgeons from departments who are at the forefront of EPR implementation and use. These individuals may not be representative of all UK cataract surgeons and in this respect may bias the sample. Furthermore, across the eight sites, the 50 consultant and other grades of surgeons did not contribute equal (or proportional) numbers of operations to the data set, although no individual surgeon contributed more than $4.9 \%$ of the total number of operations and no unit accounted for more than $23 \%$. Finally, three variables that were not part of the mandatory minimum data set are included in the analysis even though data collection is incomplete (waiting times $53.7 \%$, ethnic origin $52.6 \%$, acuity in both eyes $64.0 \%$ ). It is not known whether this had an impact on the observed results. All variables from the mandatory minimum data set reported had less than $1.6 \%$ missing data. While making data collection mandatory is desirable this must be balanced against what is practical in a clinical situation where the EPR system is being routinely used. The rules on data collection should be driven by the desire/requirement for specified outputs. Initiatives such as the Cataract National Dataset will help all EPR companies in the future and reduce the difficulties experienced during this study of combining data sets from different systems.

The findings of this study support the results of Frost et $a l^{8}$ that there is only a small disparity between capacity and population requirements for cataract surgery in the UK. Expansion of capacity should be carefully targeted and based on secure epidemiological data. This is the first major collaborative ophthalmological study in the UK to harness the benefits of EPR to rapidly and costeffectively provide detailed service delivery data. With modest investment, the data collection methods employed in this pilot study could form a template for comprehensive recording and monitoring of surgical access and clinical outcomes in the future and be the basis for ongoing routine collection of a Cataract National Dataset.

\section{Acknowledgements}

We are grateful to all the ophthalmologists who contributed data to this survey, without whose support it would not have been possible. No funding from any source was provided for this study.

Bath Royal United Hospital: JE Boulton, J Luck, S Webber, R Antcliff, R Baer, D Chelvanayagam, P Galloway.

Bradford Royal Infirmary: A Reynolds.

Bristol Eye Hospital: C Bailey, A Churchill, S Cook, J Diamond, M Greaney, R Grey, R Harrad, R Haynes, R Markham, M Potts, J Sparrow, D Tole, R Ellingham, C Gibbon, J Hale, E Hughes, R Lee, Y Ramkissoon, T Stumpf, P Summich, A Waldock.

Clayton Hospital: E Barnes, F Howes, L Ilari, M Nagar, K Pauw, S Sharma, I Simmons, K Toor, R Gupta, D Chacko, I Kravaritis, S Mishra, S Padroni, S Padroni, M Rayside, M Saldana-Valez, D Chacko, E Luhishi, M Nagar, M Saldana Velez.

Gloucestershire Hospitals NHS Trust: RL Johnston, NC Price, M Yagoubi, A James, S Asteriadis, E Rom, D Schultz, R Gale, C Lee, D Ratiram, J McCoombes, S Pathai, B Subramaniam, F Kherdaji, N Saha, K Arun, J Ferris.

Leeds Teaching Hospitals NHS Trust: A Cassels-Brown, TR Dabbs, M McKibbin, A Morrell, I Simmons, S Ahmed, A Agrawal, S Ahmed, S Anand, F Bishop, F Cuthbertson, A Das, L Downey, C Funnell, S Ghazawy, S Goel, M Khandwala, S Kolli, N Kumar, I Kundi, M Mohamed, B Pal, A Patel, B Patil, A Ruigrok, R Seemongal-Dass, Z Saihan, R Setty, A Singh, N Topping.

Norfolk and Norwich NHS Trust/Cromer: N Astbury, T Burton, T Eke, C Illingworth, C Jones, J Knight, J Khan, A Glenn, A Hatoum, J Knight, C Rai, R Shenoy. Southampton Eye Unit: CR Canning, R Newsom, RJ Morris, JA Watts, JI McGill, RM Manners, JD Macleod, AJ Luff, A Lotery, PR Hodgkins, IH Chisholm, N Amerasinghe, V Barrett, A Booth, C Cates, J Clarke, M Costen, E Elliott, D Fahy, H Gaston, S Goverdhan, R Goyal, A Gupta, N Hall, T Hardy, PR Hodgkins, ARI Ismail, T Jordan, S Karadia, J Kersey, S Khandhadia, D Khan-Lim, S Lash, A Lotery, S Madill, C Marsh, W Meacock, M Mitra, Q Mohammed, B Parkin, S Perera, G Reddy, S Rogers, J Rossiter, I Rostom, D Sahu, M Saloojee, J Self, J Sheqem, N Sinclair, T Sleep, J Spinks, B Talbot, TJ Thornton, C Tinley, JA Watts, C Williams, $\mathrm{R}$ Wintle.

\section{References}

1 Department of Health Hospital Episode Statistics. www.doh.gov.uk/hes/free_data.

2 Courtney P. The National Cataract Surgery Survey: I. Method and descriptive features. Eye 1992; 6: 487-492. 
3 Desai P. The National Cataract Surgery Survey: II. Clinical outcomes. Eye 1993; 7: 489-494.

4 Desai P. The National Cataract Surgery Survey: III. Process features. Eye 1993; 7: 667-671.

5 Desai P, Reidy A, Minassian DC. Profile of patients presenting for cataract surgery in the UK: national data collection. Br J Ophthalmol 1999; 83: 893-896.
6 Desai P, Minassian DC, Reidy A. National cataract surgery survey 1997-8: a report of the results of the clinical outcomes. Br J Ophthalmol 1999; 83: 1336-1340.

7 The NHS Plan www.nhs.uk/nationalplan.

8 Frost A, Hopper C, Frankel S, Peters TJ, Durant J, Sparrow J. The population requirement for cataract extraction: a crosssectional study. Eye 2001; 15: 745-752. 